Copyright 2020 Society of Photo-Optical Instrumentation Engineers. One print or electronic copy may be made for personal use only. Systematic reproduction and distribution, duplication of any material in this paper for a fee or for commercial purposes, or modification of the content of the paper are prohibited. 


\section{Applied Remote Sensing}

\section{Impacts of spatial heterogeneity patterns on long-term trends of Moderate Resolution Imaging Spectroradiometer (MODIS) land surface temperature time series}

Noppachai Wongsai

Sangdao Wongsai

Apiradee Lim

Don McNeil

Alfredo R. Huete

Noppachai Wongsai, Sangdao Wongsai, Apiradee Lim, Don McNeil, Alfredo R. Huete, "Impacts of spatial heterogeneity patterns on long-term trends of Moderate Resolution Imaging 


\title{
Impacts of spatial heterogeneity patterns on long-term trends of Moderate Resolution Imaging Spectroradiometer (MODIS) land surface temperature time series
}

\author{
Noppachai Wongsai, ${ }^{\text {a,c }}$ Sangdao Wongsai, ${ }^{\text {b,* }}$ Apiradee Lim,,${ }^{\text {a,c }}$ \\ Don McNeil, ${ }^{a}$ and Alfredo R. Huete ${ }^{\mathrm{d}}$ \\ ${ }^{a}$ Prince of Songkla University, Department of Mathematics and Computer Science, \\ Faculty of Science and Technology, Pattani, Thailand \\ ${ }^{\mathrm{b}}$ Thammasat University, Department of Mathematics and Statistics, Faculty of Science and \\ Technology, Pathum Thani, Thailand \\ ${ }^{c}$ Mahidol University, Centre of Excellence in Mathematics, Faculty of Science, Bangkok, \\ Thailand \\ ${ }^{\mathrm{d}}$ University of Technology Sydney, School of Life Sciences, Ultimo, New South Wales, \\ Australia
}

\begin{abstract}
Land surface temperature (LST) is a crucial parameter for global climate change studies. LST changes are also directly associated with the large-scale changes in land cover. Previous studies carried out a comparative analysis of satellite-derived LST response between periods before and after homogenous land cover changes. We present an alternative approach that quantifies long-term LST variability in response to various land use/land cover change (LULCC) patterns over Phuket Island, Thailand, from 2003 to 2017. First, four Moderate Resolution Imaging Spectroradiometer (MODIS) overpass times of LST time series were adjusted for seasonal effects using a cubic spline function to preserve the number of original data and enable estimates of LST dynamics and trends using the generalized least squared models. Second, LULCC patterns were classified according to land cover type conversion and spatial pattern transformations between the years 2000 and 2016. Spatial homogeneity and heterogeneity were quantified by the coverage percentage for each land use and land cover (LULC) type within a given location. Finally, the influence of LULCC patterns on the long-term spatiotemporal behavior of LST was assessed using the generalized estimating equation model. Results showed that different land cover transitions influence the dynamics of daytime LST but not the nighttime LST. The proportion of different land cover types within an LST pixel and transition amounts contributed to the quantity of increasing surface temperature, especially over impervious surface types. Diverse LULCC patterns with considerations of spatial heterogeneity improved our insight about a relatively strong effect of combined LULC types on LST responses. The climatic effect through the gradual conversion of heterogeneous land cover is necessary to be considered in climate research studies. (C) 2020 Society of Photo-Optical Instrumentation Engineers (SPIE) [DOI: 10.1117/1.JRS.14.014513]
\end{abstract}

Keywords: land surface temperature; MODIS; land use/land cover change pattern; trend analysis; tropical climate; Phuket Island.

Paper 190496 received Jul. 1, 2019; accepted for publication Jan. 7, 2020; published online Jan. $31,2020$.

\section{Introduction}

Population growth and economic expansion, especially in developing countries, have been the primary drivers of land use and land cover change (LULCC). High demand for cultivated and urban residential land for sustenance and a prosperous economy plays a significant role in land

*Address all correspondence to Sangdao Wongsai, E-mail: sangdao.mathstat@gmail.com

$1931-3195 / 2020 / \$ 28.00$ (c) 2020 SPIE 
transformations and losses in vegetation abundance, which are influential primary factors in land surface temperature (LST) measurement. Change in land use/land cover (LULC) not only results in habitat losses of important plant species, ${ }^{1,2}$ endangered animals, and terrestrial biodiversity, ${ }^{3}$ but also affects the biophysical characteristics of many of Earth's surface parameters. LULCC has contributed to global warming and affects urban heat island (UHI) intensity, mainly through the processes of urban extension ${ }^{4-8}$ and degradation of vegetation cover. ${ }^{910}$ Haddad et al. ${ }^{11}$ reported that LULCC could alter atmospheric rainfall and temperature patterns, affect climate at different scales (regional, local, and microclimate), and impact various ecosystems, including urban environments, ${ }^{12-14}$ grassland ecosystems,${ }^{15}$ equatorial mountain ranges,${ }^{16}$ and irrigated agricultural areas. ${ }^{17}$ Thus, comprehensive knowledge of the underlying mechanisms, patterns, and processes of land cover conversion and relationships between land use, UHI effect, and regional climate change are vital to informed decision-making processes in response to climate change of urban areas, which, in turn, improves the scientific basis of future planning and regulations. ${ }^{18}$

A number of studies have used various station-based and satellite-based data to determine the spatiotemporal relationships between surface temperature and changes in land cover. ${ }^{6,19}$ These studies found that near-surface air temperature and LST are sensitive and strongly related to LULCCs, especially in urban areas. ${ }^{5,13,20-22}$ Many previous studies have also used a few satellite images to analyze the impact of land conversion on LST but without fully considering the temporal features of reflective and thermal data. Sahana et al. ${ }^{23}$ and Kayet et al. ${ }^{24}$ used decadal separated Landsat images to study the impact of LULC conversion on LST distributions. They used various remote sensing techniques to detect land use changes and assess their impact on surface temperature and variations over the hot spots of land cover conversion. They found substantial increases in LST with the loss of vegetated areas. Chen et al. ${ }^{5}$ used remote sensing images from the years 1990 and 2000 in the Pearl River Delta area, south of China, to explore the relationship between temperature and LULC changes at regional and local scale utilizing vegetation, water, bareness, and built-up indices. Their results showed the UHI effect to be more prominent in areas of rapid urbanization. Li et al.$^{25}$ utilized the coupling of remotely sensed data acquired in 1997 and 2004 to quantitatively characterize patterns of UHI in Shanghai, China. The study revealed a significant increase of magnitude in UHI intensity and its spatial extent mainly caused by the rapid growth of urbanized area, which was consistent with the study of Xiong et al., ${ }^{26}$ which observed that the urban thermal environment could be attributed to rapid urbanization, especially by the expanding built-up areas and developing land and to the declining vegetation coverage.

High temporal resolution satellite-derived LST and land cover data were used in time series analysis of the LST dynamic caused by the change of land cover. Hereher ${ }^{27}$ used 299 satellite images acquired from the Moderate Resolution Imaging Spectroradiometer (MODIS) LST product for the period between 2003 and 2015 to address the change in LST resulting from the emergence and disappearance of lakes, as the main LULCC, in the Western desert of Egypt. Their study highlighted the occurrence of a severe heat island effect caused by comparing annual and 13-year mean LST trends. The method of averaging high temporal LST data was usually used to eliminate the seasonal effect of the time series. However, this reduces the number of observed data, making inferential statistical analysis less effective, and thus only comparative analysis is an appropriate method for trend analysis. Fu and Weng ${ }^{28}$ conducted a time series analysis of urbanization-induced LULCC using 507 Landsat L1T images from 1984 to 2011. The satellite images were classified and detected for LULC change. LST time series were also extracted from the image series and further decomposed into seasonal and trend components through an additive model. Decomposition analysis showed that the conversion of evergreen forest to medium-intensity urban land generated the most significant changes in annual LST variation and the most considerable LST trend differences.

Previous studies have focused solely on the LST effect from one individual LULCC pattern and assume a uniform land cover type within a given coarse resolution LST pixel for simplicity. Moreover, few studies have concerned the effect of spatial heterogeneity of land cover within low-resolution LST pixels, such as 1-km MODIS LSTs that could affect the variation of LST trend. Zhang and Liang ${ }^{29}$ investigated the impact of different transitions of land cover on LST over China. They computed pixelwise MODIS LST changes ( $\Delta$ LST) over different classes of 
land cover transition, as well as different percentage levels of transition, based on averages of monthly LST data across 3 years $(2001,2006$, and 2011). Their quantile regression results show that LST (both day and night time) changes were, on the whole, relatively limited and uncertain. LST changes were not only found in areas where transitions occurred but also in the area without transition. An increasing amount of change from cropland to built-up area within MODIS pixel $\left(1 \times 1 \mathrm{~km}^{2}\right)$ resulted in LST increases both in daytime and nighttime. However, their results did not confirm the impact of LULCC with different percentages of land cover transition on LST over China.

The objective of this study is to demonstrate an alternative approach for estimating the impact of LULCC on long-term LST variability and trends. Unlike previous studies that quantify impacts of land cover conversion on LST through comparing annual average satellite-derived LST from the period before and after the transition, this study utilized 15 years of 8-day composite MODIS LST time series to assess the spatiotemporal dynamics of LST over the study area. Time-series analyses, including explicitly performed seasonally adjusted LST time series to preserve the number of data observations and linear trend estimation, were conducted to expose the influence of land conversion on the long-term surface temperature dynamics. We also considered different transition patterns and the proportion of transition amounts from individual land cover types. Such time series analysis using a combination of statistical methods with consideration of statistical assumptions leads to a better understanding and firmer evidence-based conclusions of an LST trend and its drivers.

\section{Materials and Methods}

\subsection{Study Area}

Figure 1 illustrates the study area. Phuket Island is the largest island situated off the southwest coast of Thailand [Fig. 1(a)]. The total area of the island is about $532 \mathrm{~km}^{2}$, with a length of

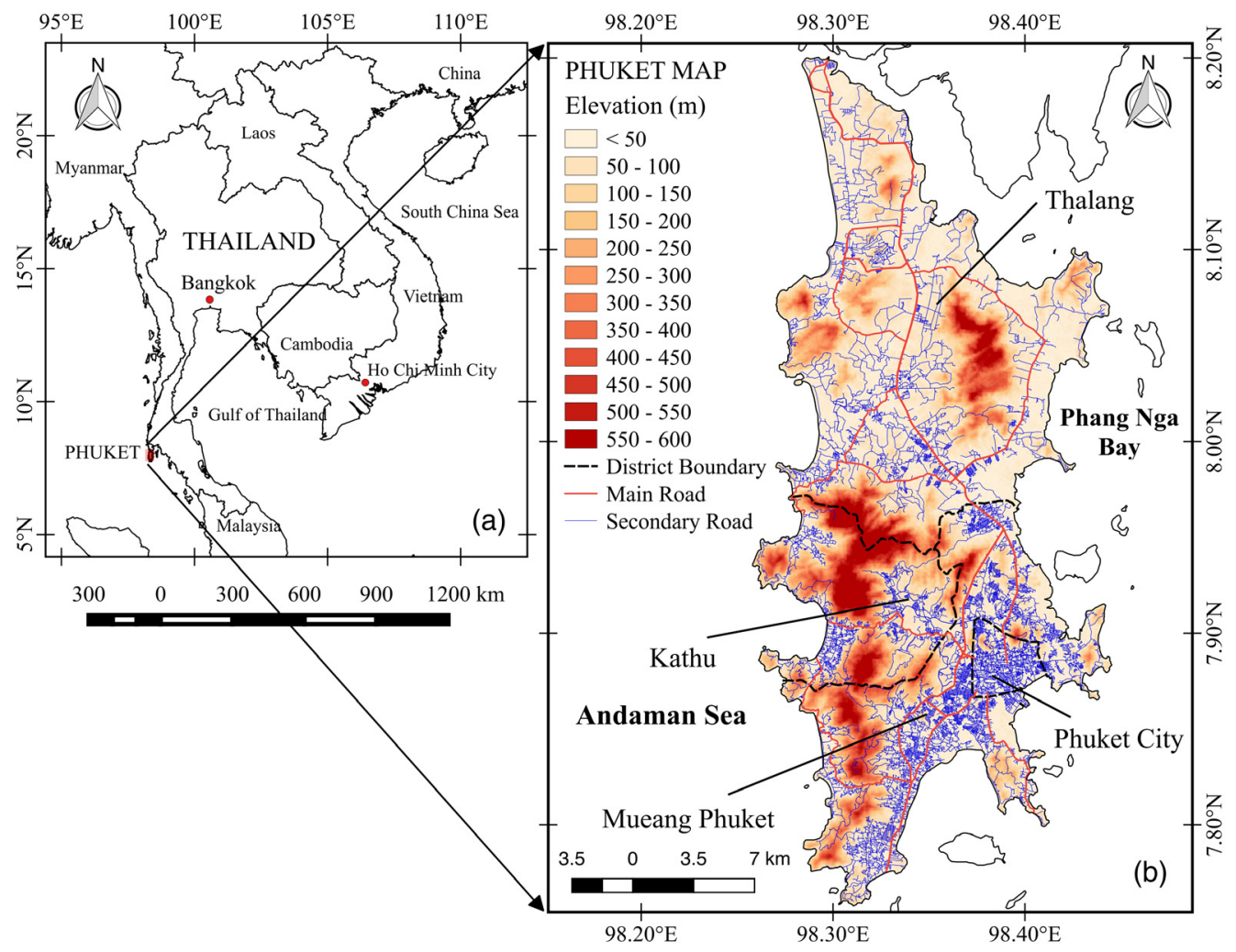

Fig. 1 (a) Map of Thailand and (b) geographical map of Phuket Island including elevation, roads, and four administrative boundaries. 
$48.7 \mathrm{~km}$ from north to south and a width of $21.3 \mathrm{~km}$ from west to east. Approximately $65 \%$ of the island area, as shown in Fig. 1(b), is the high mountain range that runs along the southwestern shore from the north to the south direction. The highest peak is about $582 \mathrm{~m}$ above average sea level. Its west coast facing the Andaman Sea (a marginal sea of the eastern Indian Ocean) has many magnificent long sandy beaches. In contrast, its eastern shoreline, which is facing Pahang Nga Bay, contains many dense mangrove forests.

Phuket Island is divided into three administrative districts [Fig. 1(b)], namely, Mueang Phuket, Kathu, and Thalang. Mueang Phuket district has a local administration, namely Phuket City, with the highest density of residential and commercial buildings. The island interior is mostly mountainous while the lowland occupies most of the Thalang district area where the major agricultural area is located. The high mountains cover $\sim 80 \%$ of the Kathu district area and about $35 \%$ of the southwest region of the Mueang Phuket district area. Phuket is considered as the major capital in Thailand's southwest region (also called the Andaman Coast region) with a population of nearly 400,000 according to a register-based census in 2014 . However, it is expected that the real number of its people could reach 600,000 because there are labor migrants from other parts of Thailand and neighboring countries living on the island that have not been recorded in the census database. Phuket formerly derived its wealth from the tin mining industry since the early 15 th century until 1992 when the last mine was closed. The island now earns much of its income from tourism. In 2014, Phuket welcomed more than 11.9 million visitors and brought in about 260 billion Baht (nearly 7.3 USD billion), accounting for $50 \%$ of the country's tourism revenue. Most of the developments and infrastructures on the island during the last two decades have been driven by the massive growth of the tourism industry. Consequently, Phuket is experiencing significant LULC changes due to the rapid growth of urbanization and local economic exploitation of natural resources. ${ }^{30}$

\subsection{Data}

\subsubsection{Land Use and Land Cover}

LULC data for years 2000 (LU2000) and 2016 (LU2016) were obtained from the Land Development Department (LDD), Ministry of Agriculture and Cooperatives of Thailand. LDD is responsible for surveying LULC for every province in Thailand since 1967. According to LDD, the secondary LULC data were initially generated in vector format (shapefile map) by digitizing high spatial resolution aerial photography $(1 \mathrm{~m})$ released around 1 year after the survey project started. A new land use map was developed on top of the previous map. Aerial photo

Table 1 LULC type and its description.

\begin{tabular}{ll}
\hline \hline LULC type & \multicolumn{1}{c}{ Description } \\
\hline Forest land (F) & $\begin{array}{l}\text { All dense evergreen and deciduous forests either as forest under any } \\
\text { legal enactment, whether state-owned or private, as well as a dense and } \\
\text { disturbed mangrove forest. }\end{array}$ \\
Agricultural land (A) & $\begin{array}{l}\text { All cultivable land and land under plantations (both small private plantations } \\
\text { and commercial plantations), e.g., paddy fields (abandoned and active), } \\
\text { para rubber plantations, mixed orchards (perennial fruit trees), coconut } \\
\text { orchards, as well as all land utilized for field crops, horticulture, pasture and } \\
\text { farmhouse, and aquatic plants. }\end{array}$ \\
All land occupied by buildings in both urban and rural such as city, town, \\
and commercial areas, villages (low land), and recreation areas such as \\
land (U)
\end{tabular}


interpretation and ground survey were conducted for land use classification. There are three levels of land use types classified according to LDD definitions. The first level comprises five primary types. Table 1 shows a detailed description of five major types: forest $(\mathrm{F})$, agricultural (A), urban and built-up (U), water body (W), and bare land (B). In this study, farm ponds, fish, and shrimp farms that were initially classified by LDD as agricultural land were redigitized and reclassed into water bodies.

\subsubsection{MODIS LST data}

In this study, we used both daytime and nighttime level-3 LST products from two MODIS sensors (Terra and Aqua platforms). Both space-borne sensors detect and measure the Earth's surface temperature four times a day, which are 10:00/22:00 (Terra) and 14:00/02:00 (Aqua) at local overpass times. The Collection 6 (C6) eight-day composite Global 1-km sinusoidal tile Grid MODIS LST/emissivity products located over the study area were downloaded from the MODIS subset tool. ${ }^{31}$ We also used the MODIS product quality control layers (QC_day and QC_night) that provide information on the accuracy of the retrievals. The additional information on algorithm results for each pixel was used to determine a set of weight scores. It was used in seasonal modeling using an annual periodic boundary cubic spline function in the seasonal adjustment of LST time series to preserve the number of original LST data. ${ }^{32}$ The best QC values have an average error of $<1$ Kelvin $(\mathrm{K})$, while the worst QC values have an average error of $3 \mathrm{~K}$ or more. ${ }^{33}$ Other previous MODIS LST studies usually disregard LSTs with low-quality QC value. However, we used all the obtained LST data in our study, but the low QC LSTs contributed less in the regression analysis with the weight scores.

MODIS LST products are globally validated in physical radiance units over large uniform areas, such as water bodies and under clear sky conditions through aircraft and field campaigns. ${ }^{34-36}$ The evaluation of the absolute radiometric accuracy of MODIS LST data against in situ measurements has been conducted, and the results showed good performances in many large homogeneous surface study areas, such as lake, ${ }^{37-39}$ rich field, ${ }^{35,40}$ grass/cropland, ${ }^{41,42}$ and arid areas. ${ }^{43}$ However, the accuracy over other homogeneous and heterogenous surfaces could be relatively lower. It is very difficult for validating large 1-km MODIS LST pixels, especially when affected by clouds and heavy aerosols. Severely contaminated LSTs are removed in level-3 C6 MODIS LST products using empirical constraints on temporal variations in clear-sky LSTs. ${ }^{33}$ The available quality assurance provides information on the possible contaminants, such as subpixel cloud presence in MODIS data, which should be considered for applications. In this study, C6 MODIS LST data from MOD11A2 start from March 5, 2000, which is 2 years earlier than the data from MYD11A2. Thus, we decided to select LST data from the years 2003 to 2017, comprising 690 observations in total (46 observations each year) for the simplicity of data processing and comparison of results.

\subsection{Data Analysis}

\subsubsection{LULC Change and Its Patterns}

LU2000 and LU2016 data were managed in the open-source QGISplatform. ${ }^{44}$ Overall, LULCC in the entire study area and by four subregions (Mueang Phuket, Kathu, Thalang, and Phuket City) from 2000 to 2016 were examined by a transition matrix.

For LULCC pattern identification, we first determined the area of LULC type within a $1 \times$ $1 \mathrm{~km}^{2}$ MODIS LST pixel. Polygons in the WGS84 coordinate system that match the sinusoidal MODIS LST pixels were generated over the study area using projection/grid conventional formulas. ${ }^{45}$ Here, we are given the row $(i)$ and column $(j)$ in MODIS tile $H, V$. First, compute the position of the center of the grid cell on the global sinusoidal grid:

$$
\begin{aligned}
& x=(j+0.5) \omega+H T+x_{\min }, \\
& y=y_{\max }-(j+0.5) \omega-V T .
\end{aligned}
$$


Next, compute the latitude $(\varnothing)$ and longitude $(\lambda)$ at the center of the grid cell (in radians):

$$
\begin{gathered}
\varnothing=y / R, \\
\lambda=x / R \cos (\varnothing),
\end{gathered}
$$

where $R=6371007.181 \mathrm{~m}, T=1111950 \mathrm{~m}, x_{\min }=20015109 \mathrm{~m}, y_{\max }=10007555 \mathrm{~m}$, and $\omega=T / 1200=926.625 \mathrm{~m}$, the actual size of a "1 km" MODIS sinusoidal grid cell. However, the coordinates of the four corners of the pixel can be obtained directly by adding \pm 0.5 to the row $(i)$ and column $(j)$ as desired.

Then, the coordinates were formed as the vector geometry of polygon objects in the wellknown text (WKT) format, originally defined by the Open Geospatial Consortium. The WKT file was imported to QGIS and then converted to a shapefile format. Finally, LU2000, LU2016, and LST polygon layers were intersected using geoprocessing tools. Second, we defined six LULC classes by assigning a LULC type to each LST pixel according to its percentage of a combined area-based condition by following the classification rules described in Table 2. A bin width of $20 \%$ was suggested to ensure the lowest percentage of area in the case when all five types are found within a pixel. The higher the portion in a class the greater homogeneity the LULC type. Classes 1 and 2 are labeled to homogeneous land with at least $80 \%$ of the total area belonging to only one LULC type, whereas classes 3 to 6 are entitled to heterogeneous land with one or two dominant types.

Table 3 shows four categories of LULCC pattern and their criteria for a comparison of individual classes from two different periods, allowing us to explore pattern differences in spatial homogeneity and heterogeneity. In this study, a change is referred to as LULC type transformation over time and heterogeneity is denoted by the coverage percentage for each LULC type

Table 2 LULC classes and their corresponding classification rules based on the percentage of a combined area within the $1 \times 1 \mathrm{~km}^{2}$ LST pixel.

\begin{tabular}{llcc}
\hline \hline Class & \multicolumn{1}{c}{ LULC type selection } & \% of Domination area & Example \\
\hline 1 & One LULC type (first maximum) & $100 \%$ & $\mathrm{~F}_{1}$ \\
2 & One LULC type (first maximum) & $>80 \%$ & $\mathrm{~A}_{2}$ \\
3 & One LULC type (first maximum) & $60 \%-80 \%$ & $\mathrm{U}_{3}$ \\
4 & One LULC type (first maximum) & $40 \%-60 \%$ & $\mathrm{~W}_{4}$ \\
5 & Two LULC types (first and second maximum) & $40 \%-60 \%$ & $\mathrm{AU}_{5}$ \\
6 & Two LULC types (first and second maximum) & $<40 \%$ & $\mathrm{UA}_{6}$ \\
\hline \hline
\end{tabular}

Table 3 LULCC pattern categories and their corresponding criteria.

\begin{tabular}{lcccc}
\hline \hline Category & 2000 & $->$ & 2016 & Example \\
\hline Homogeneous unchanged (HoU) & LULC $_{1,2}$ & $=$ & LULC $_{1,2}$ & HoU-A \\
Homogeneous changed (HoC) & $\mathrm{A}_{1}$ & $->$ & $\mathrm{A}_{2}$ & \\
& $\mathrm{LULC}_{1,2}$ & $\neq$ & LULC $_{1,2}$ & HoC-AU \\
Heterogeneous unchanged (HeU) & $\mathrm{A}_{2}$ & $->$ & $\mathrm{U}_{2}$ & \\
& $\mathrm{LULC}_{3,4,5,6}$ & $=$ & LULC $_{3,4,5,6}$ & HeU-F \\
Heterogeneous changed $(\mathrm{HeC})$ & $\mathrm{F}_{3}$ & $->$ & $\mathrm{F}_{4}$ & \\
& $\mathrm{LULC}_{3,4,5,6}$ & $\neq$ & LULC $_{3,4,5,6}$ & HeC-AUa \\
\hline \hline
\end{tabular}


in a pixel. When considering homogeneous classes 1 and 2, if the dominant LULC type is unchanged over time, and its area coverage is at least $80 \%$, then it is defined as homogeneous unchanged type category (HoU). Conversely, if dominated LULC type is changed by at least $80 \%$ of its area conversion during the study period, then it is defined as homogeneous changed type category (HoC). A similar rule was applied when considering heterogeneous classes 3 to 6 . Heterogeneous unchanged type category (HeU) and heterogeneous changed type category $(\mathrm{HeC})$ are denoted for the unchanged and changed types with varying coverage percentages, respectively. We intentionally proposed the systematic criteria used as the classifying conditions to be employed in other study areas at any scale. By using this proposed criteria, we can categorize land cover change patterns with different degrees of spatial heterogenicity. Thus, we can gain the inside information of the effects of spatial heterogenicity for particular land cover conversion patterns on LST trend using appropriate statistical methods.

\subsubsection{Seasonally adjusted LST time series}

We adopted a spline-based method ${ }^{32}$ to remove the seasonal effect from eight-day composite MODIS LST time series data. A summary of the method is described as follows: The cubic spline with annual periodic boundary condition was derived for extracting interannual seasonality in LST data series. The cubic spline function can be expressed in the following equation:

$$
s(t)=a+b t+\sum_{k=1}^{p-3} c_{k}\left[\left(t-t_{k}\right)_{+}^{3}-d\left(t-t_{p-2}\right)_{+}^{3}+e\left(t-t_{p-1}\right)_{+}^{3}-f\left(t-t_{p}\right)_{+}^{3}\right],
$$

where $d=\frac{\left(t_{p}-t_{k}\right)\left(t_{p-1}-t_{k}\right)}{\left(t_{p-1}-t_{p-2}\right)\left(t_{p}-t_{p-2}\right)}, e=\frac{\left(t_{p-2}-t_{k}\right)\left(t_{p}-t_{k}\right)}{\left(t_{p-1}-t_{p-2}\right)\left(t_{p}-t_{p-1}\right)}$, and $f=\frac{\left(t_{p-2}-t_{k}\right)\left(t_{p-1}-t_{k}\right)}{\left(t_{p}-t_{p-2}\right)\left(t_{p}-t_{p-1}\right)}$.

This cubic spline function is aimed to detect the annual climatological profile by fitting it on all 15-year data series reordered into Julian days. Extreme LST values need to be identified using interquartile range (IQR). LST values at a particular Julian day higher than 1.5 times of the IQR above the third quartile or below the first quartile were marked as outliers. To fit the cubic spline function to the data, we applied weighted least squares regression with propensity scores according to the QC layers of the obtained LST data. With this method, high-quality LSTs, which refers to a low average LST error in Kelvin degrees, would have a higher impact on the estimation of regression coefficient than low-quality LSTs. In this study, we give zero weight to all the extreme LSTs and give a score of 10 when an average LST error $\leq 1 \mathrm{~K}, 5$ for an error $\leq 2 \mathrm{~K}, 2$ for an error $\leq 3 \mathrm{~K}$, and 1 for an error $>3 \mathrm{~K}$.

Once the seasonal effect is estimated, the seasonally adjusted LST can be computed by subtracting the original LST data series from the seasonal component and then adding the difference of the averaged LST component and the averaged seasonal subtracted LST, denoted as follows:

$$
\mathrm{LST}_{\mathrm{s.adj}}=1 \mathrm{st}_{i}-\mathrm{S}_{i}+\left(\sum_{i=1}^{n} \frac{1 \mathrm{st}_{i}}{n}-\sum_{i=1}^{n} \frac{1 \mathrm{st}_{i}-\mathrm{S}_{i}}{n}\right),
$$

where $S$ is the seasonal component and $i$ is the ordered observation in the data series. From this point forward, a term of LST is referred to as a seasonally adjusted LST using the method described in this section.

\subsubsection{Statistical analysis of spatial and temporal data}

We first fitted a generalized least squares (GLS) model to 690 observed LST data for each pixel to estimate the slope coefficient, indicating an increasing or decreasing trend over 15 years of the study period. GLS is a modification of ordinary least squares (OLS) that accounts for covariance among observations on the dependent variable. Although the acquired MOD11A2 and MYD11A2 products were generated from MODIS daily products by eight-day composition and the seasonal effect was eliminated from the original LST time series, there was a certain degree of autocorrelation, where the value of LST affects its future value. This causes a problem in satisfying statistical assumptions of uncorrelated observations and equality of sampling variances in 
the OLS, and thus, the OLS-fitted coefficients could be inaccurate relative to GLS-fitted coefficients. The processes of statistical model fitting were conducted in $\mathrm{R}$ platform ${ }^{46}$ using its nlme package. ${ }^{47}$ For a particular pixel, long-term LST series were individually fitted using the $\mathrm{g} l \mathrm{~s}()$ function with CorAR1 as the correlation structure class. This AR(1) correlation structure represents an autocorrelation structure of order $1{ }^{48,49} \mathrm{An}$ increasing or decreasing trend of LST and its corresponding $p$-value of model fitting were obtained for each LST pixel (location) and then illustrated as thematic maps for spatial inspection.

For each LULCC pattern, we then fitted generalized estimating equations (GEEs), available from the R geepack package, ${ }^{50}$ to the LST data. GEE is an appropriate model because it is generally applied for repeated measures in longitudinal and clustered data analysis. ${ }^{51,52}$ In this study, LST at a given pixel was repeatedly measured for 690 time points. Such longitudinal LST data were then clustered by a correlation link of the pixel identification number. GEE is a semiparametric population-averaged model that focuses on the aggregate response for the population. ${ }^{53}$ It estimates the marginal model parameters and their standard errors. Hence, the estimated slope coefficient of the fitted model between LST and observed times, its corresponding $p$-value for the fixed effect of repeated measures, and a 95\% confidence interval (CI) were obtained. Similarly, we also fitted the GEE model to the LST data in the area where the land cover was transformed to urban with different amounts of built-up fragments to examine the impact of heterogeneity in long-term LST change during the study period.

\section{Results}

\subsection{LULCC of Phuket During 2000 to 2016}

LULC maps are illustrated in Fig. 2, and their corresponding LULCCs from 2000 to 2016 over Phuket Island are given in Table 4, respectively. Agricultural land degradation accounted for the most substantial proportion of land conversion during the study period. It declined from 292.2 to $184.5 \mathrm{~km}^{2}$ (20.8\% of the total area) due to urban expansion and reforestation. Other types of land were expanded and ranked in descending order for urban (10.0\%), bare land (5.4\%), forest (3.9\%), and water bodies (1.6\%), respectively.

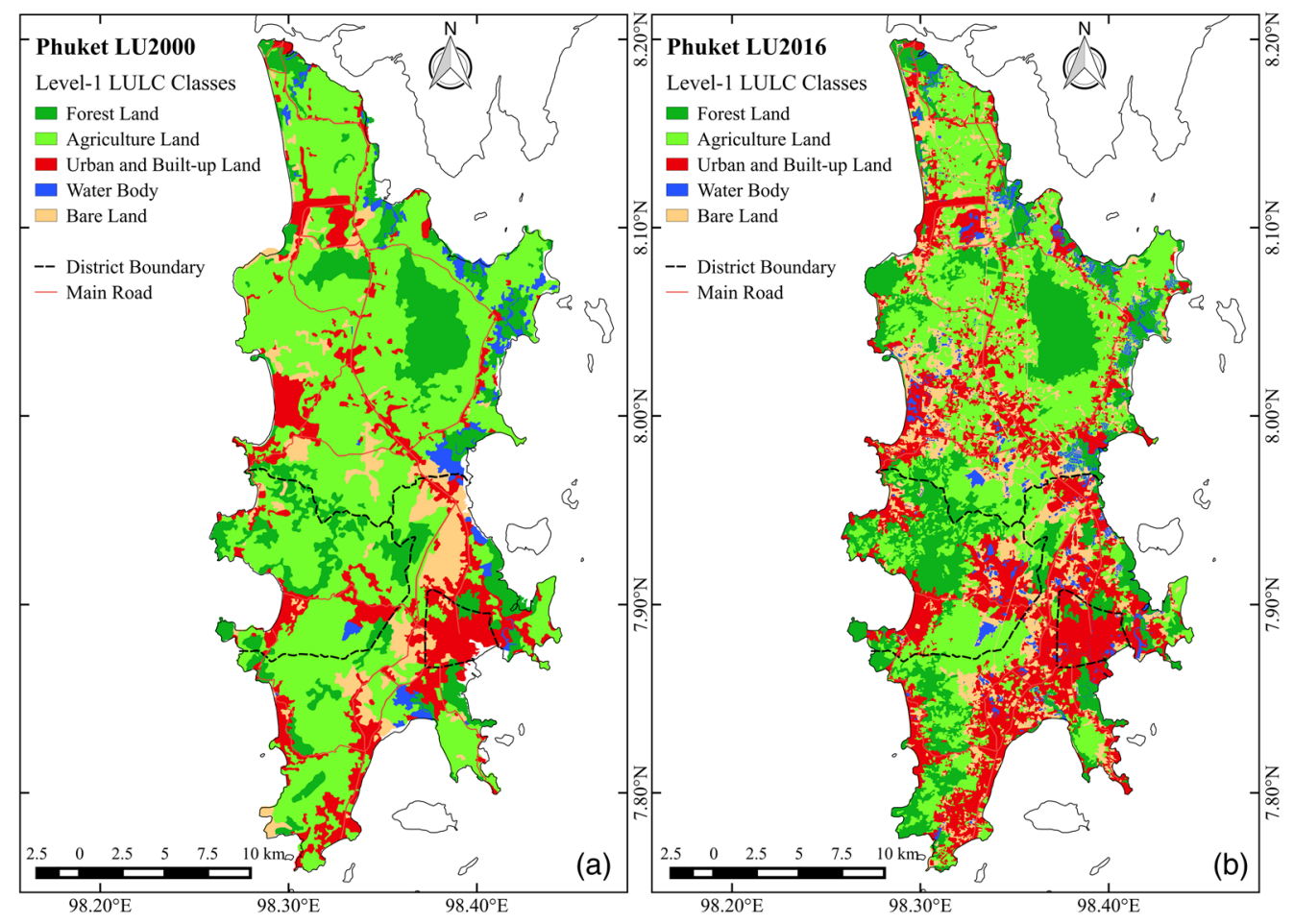

Fig. 2 Land use and land cover maps in (a) 2000 and (b) 2016. 
Table 4 LULC transition matrix between 2000 and 2016 in Phuket Island in $\mathrm{km}^{2}$. Percentage of LULC conversion is given in the brackets.

\begin{tabular}{|c|c|c|c|c|c|c|c|}
\hline \multirow{2}{*}{\multicolumn{2}{|c|}{ LULC }} & \multicolumn{5}{|c|}{2016} & \multirow[b]{2}{*}{ Total } \\
\hline & & $\mathrm{F}$ & A & U & w & B & \\
\hline \multirow[t]{5}{*}{2000} & $\mathrm{~F}$ & $57.9(64.2)$ & $17.6(19.5)$ & $7.5(8.3)$ & $3.5(3.9)$ & $3.7(4.1)$ & 90.2 \\
\hline & A & $44.1(15.1)$ & 152.5 & $52.1(17.8)$ & $5.7(2.0)$ & $37.8(12.9)$ & 292.2 \\
\hline & $U$ & $2.5(3.0)$ & $7.1(8.7)$ & $58.5(71.8)$ & $3.8(4.7)$ & $9.6(11.8)$ & 81.5 \\
\hline & W & $2.6(17.9)$ & $2.9(20.0)$ & $1.7(11.7)$ & $5.4(37.3)$ & $1.9(13.1)$ & 14.5 \\
\hline & B & $3.2(8.0)$ & $4.4(11.0)$ & $13.4(33.7)$ & $4.2(10.6)$ & $14.6(36.7)$ & 39.8 \\
\hline \multicolumn{2}{|c|}{ Total } & 110.3 & 184.5 & 133.2 & 22.6 & 67.6 & 518.2 \\
\hline \multicolumn{2}{|c|}{$\begin{array}{l}\text { Direction of } \\
\text { change }\end{array}$} & $\uparrow$ & $\downarrow$ & $\uparrow$ & $\uparrow$ & $\uparrow$ & \\
\hline
\end{tabular}

F, forest land; A, agricultural land; $U$, urban and built-up land; W, water body; and B, bare land.

Agricultural land was mainly converted to urban and bare land for supporting the economicdriven growth of tourism in Phuket during the last two decades, particularly in Mueang Phuket district and Thalang district. Not only high demand for tourism-related developing land and buildings is the significant driving force of rapid LULCC, but also the growth of population and labor migration to support tourism service sectors is another cause of urban expansion with the need for residential housing and community infrastructures ${ }^{54}$ Furthermore, a transformation of cultivation land to the forest was observed in land-reform areas, mostly on high hills of Mueang Phuket and Kathu districts. The government's land-reform scheme was first implemented in 1975, with an aim to distribute degraded forest lands to poor farmers under the conditions for temporary land tenure and utilizing given land only for cultivation. However, not all of the distributed lands were used for agriculture, in practice, because many parts of them were not worthy and suitable for cultivation (e.g., too steep, difficult to access). Thus, some areas remained uncultivated and turned gradually and naturally into a dense forest cover. Furthermore, bare land has experienced such extensive change to urban surface. Around $36.7 \%$ of bare land in year 2000 had been converted to new urban in year 2016, especially on the west of Phuket City.

\subsection{LULCC Pattern Analysis}

Table 5 shows classification results of LULCC patterns of Phuket Island from 2000 to 2016, aggregating into three levels: major, minor, and finest. At the finest level, 92 LULCC patterns were observed using the classification rules and change pattern criteria described in Sec. 2.3.1. Our study area is relatively small and experiences rapid land cover change during the study period, which causes high surface heterogeneities. Thus, there were many different change patterns with a few numbers of pixels. The individual patterns require aggregation for further statistical analysis to ensure a sufficient number of sample sizes in each change pattern. At the minor level, 15 categories were aggregated using their transformation similarity and area domination of its mixed LULC classes. HoU-A, HoU-F, and HoU-U represent the transformation from homogenous unchanged agriculture, forest, and urban, respectively. HeU-A, HeU-B, HeU-F, HeU-U, and $\mathrm{HeU}-\mathrm{W}$ represent heterogeneous unchanged agriculture, bare land, forest, urban, and water bodies. HeC-AF, HeC-AU, HeC-FM, and $\mathrm{HeC}-\mathrm{WM}$ represent heterogeneous changed pattern from agriculture to the forest, agriculture to the urban, forest to mixed types of land, and water bodies to mixed types of land. $\mathrm{HeC}-\mathrm{AMb}, \mathrm{HeC}-\mathrm{AMw}$, and $\mathrm{HeC}-\mathrm{BMu}$ represent heterogeneous changed pattern from agriculture to mixed types of land with bare land dominating, agriculture to mixed types of land with water bodies dominating, and bare land to mixed types of land with urban dominating, respectively. For simplicity of referring to the change patterns, 10 categories were defined at the major level according to whether or not the LULC type has been converted over time. Unchanged agriculture area, bare land, forest, urban, and water body were symbolized 
Wongsai et al.: Impacts of spatial heterogeneity patterns on long-term trends...

Table 5 Groups of LULC change pattern. Numbers of pixels indicated in the brackets.

\begin{tabular}{|c|c|c|}
\hline Major & Minor & Finest \\
\hline \multirow[t]{2}{*}{ AA (200) } & HoU-A (54) & HoU-A (54) \\
\hline & HeU-A (146) & HeU-A (137), HeU-AF (4), HeU-AB (1), HeC-AfA (4) \\
\hline BB (9) & HeU-B (9) & $\mathrm{HeU}-\mathrm{B}(9)$ \\
\hline \multirow[t]{2}{*}{ FF (65) } & HoU-F (17) & HeU-F (17) \\
\hline & HeU-F (48) & $\begin{array}{l}\text { HeU-F (38), HeU-FW (1), HeC-FFa (1), HeC-FFw (1), HeC-FaF (5), } \\
\text { HeC-FFu (1), HeC-FwF (1), HeC-FaAf (1) }\end{array}$ \\
\hline \multirow[t]{2}{*}{ UU (61) } & HoU-U (8) & HoU-U (8) \\
\hline & $\mathrm{HeU}-\mathrm{U}(53)$ & $\begin{array}{l}\text { HeU-U (36), HeC-UA (1), HeC-UaU (5), HeC-UfU (1), HeC-UbU (1), } \\
\text { HeC-UUb (1), HeC-UUw (1), HeC-UAu (1), HeC-UB (1), HeC-UBu (3), } \\
\text { HeC-UW (1), HeC-UWu (1) }\end{array}$ \\
\hline WW (15) & HeU-W (15) & HeU-W (15) \\
\hline \multirow[t]{3}{*}{ AM (97) } & $\mathrm{HeC}-\mathrm{AF}(62)$ & $\begin{array}{l}\text { HoC-AF (5), HeC-AF (27), HoC-AAf (8), HoC-AFa (13), HoC-AFu (2), } \\
\text { HoC-AFw (1), HoC-AfF (4), HoC-AfFa (2) }\end{array}$ \\
\hline & $\mathrm{HeC}-\mathrm{AMb}(23)$ & $\begin{array}{l}\mathrm{HeC}-\mathrm{AB}(11), \mathrm{HeC}-\mathrm{ABa}(3), \mathrm{HeC}-\mathrm{ABf}(1), \mathrm{HeC}-\mathrm{ABu} \text { (1),HeC-AfB (1), } \\
\operatorname{HeC}-\mathrm{AbBf}(1), \mathrm{HeC}-\mathrm{AAb}(5)\end{array}$ \\
\hline & $\mathrm{HeC}-\mathrm{AMw}(12)$ & $\begin{array}{l}\text { HeC-AAw (2), HeC-AW (2), HeC-AWa (3), HeC-AWf (2), HeC-AWu (1), } \\
\text { HeC-AwW (2) }\end{array}$ \\
\hline $\mathrm{AU}(92)$ & $\mathrm{HeC}-\mathrm{AU}(92)$ & $\begin{array}{l}\text { HoC-AU (4), HeC-AU (57), HeC-AAu (6), HeC-AUa (8), HeC-AUb (4), } \\
\text { HeC-AUw (1), HeC-AbU (1), HeC-AuU (9), HeC-AwU (1), HeC-AuUa (1) }\end{array}$ \\
\hline FM (25) & HeC-FM (25) & $\begin{array}{l}\text { HoC-FA (1), HeC-FA (5), HeC-FAf (3), HeC-FU (3), HeC-FUf (2), } \\
\text { HeC-FW (1), HeC-FWb (1), HeC-FaA (7), HeC-FaU (1), HeC-FwFu (1) }\end{array}$ \\
\hline $\mathrm{BU}(31)$ & $\mathrm{HeC}-\mathrm{BMu}(31)$ & $\begin{array}{l}\mathrm{HeC}-\mathrm{BU}(12), \mathrm{HeC}-\mathrm{BUb}(4), \mathrm{HeC}-\mathrm{BaAu}(1), \mathrm{HeC}-\mathrm{BaBu}(1) \\
\mathrm{HeC}-\mathrm{BaU}(2), \mathrm{HeC}-\mathrm{BuU}(1), \mathrm{HeC}-\mathrm{BAb}(1), \mathrm{HeC}-\mathrm{BF}(2), \mathrm{HeC}-\mathrm{BaA}(1) \\
\mathrm{HeC}-\mathrm{BaB}(4), \mathrm{HeC}-\mathrm{BfF}(1), \mathrm{HeC}-\mathrm{BfB}(1)\end{array}$ \\
\hline WM (16) & HeC-WM (16) & $\begin{array}{l}\text { HeC-WFw (1), HeC-WBu (1), HeC-WBw (1), HeC-WU (5), HeC-WWa (1), } \\
\text { HeC-WWf (2), HeC-WWb (1), HeC-WaW (2), HeC-WfU (1), HeC-WuUb (1) }\end{array}$ \\
\hline
\end{tabular}

as $\mathrm{AA}, \mathrm{BB}, \mathrm{FF}, \mathrm{UU}$, and $\mathrm{WW}$, respectively. AM and $\mathrm{AU}$ represent the transformation of agriculture to mixed land type and urban, and FM and WM denote conversion from forest and water body to mixed land type, respectively. BU indicates conversion of bare land to mixed land type with urban domination.

Of 612 pixels, AA, BB, FF, UU, and WW accounted for $57.2 \%$ (350 pixels), indicating $\sim 353 \mathrm{~km}^{2}$ of the dominant LULC types on the Phuket Island has not been changed over the study period. Homogeneous land with at least $80 \%$ of $1 \times 1 \mathrm{~km}^{2}$ pixel being unchanged over time; HoU-A (54), HoU-F (17), and HoU-U (8), ensuring $79 \mathrm{~km}^{2}$ (12.9\%) being almost entirely untouched land. Heterogeneous land with $40 \%$ to $80 \%$ of $1 \times 1 \mathrm{~km}^{2}$ pixel being unchanged over time; HeU-A (146), HeU-F (48), HeU-U (53), HeU-B (9), and HeU-W (15) represent $271 \mathrm{~km}^{2}$ $(44.3 \%)$ of persistent of dominant LULC type being moderately transformed.

HoU-A and HeU-A were the most land cover change patterns found on the low and high ground in the study area [Fig. 3(a)]. HoU-F was found on high mountain range enclosed within Khao Phra Thaeo Wildlife Sanctuary area in the Thalang district, whereas HeU-F was found close to the shore (mangrove forest blended with aquaculture farms) and around the foothills (rainforest mixed with rubber plantations). HoU-U was unsurprisingly found in the Phuket City area, where building and housing have been fully developed. HeU-U was noticed along the western coastline, where the famous beaches and numerous vacation facilities (resorts and hotels) are situated.

LULC transformation in terms of types and corresponding area coverage was observed for $42.8 \%$ (262 pixels), comprising AM (97 pixels, $15.8 \%$ of the total pixels), $\mathrm{AU}(92,15.0 \%)$, BU 


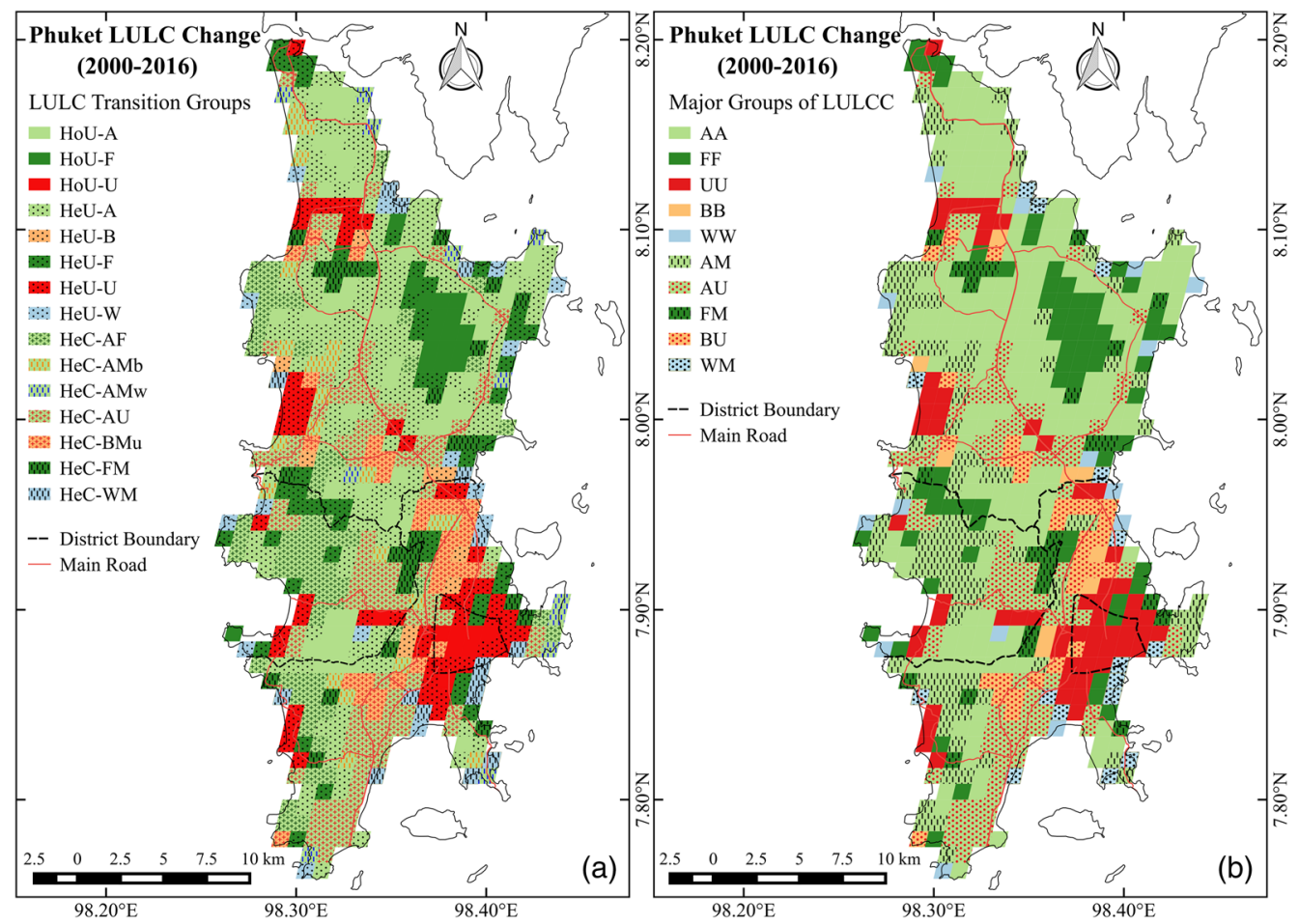

Fig. 3 (a) The original LULC conversion map classified using area-based criteria described in Tables 2 and 3 and (b) the regrouping LULC conversion map for inferential analysis, as detailed in Table 5.

$(31,5.1 \%), F M(25,4.1 \%)$, and WM $(16,2.8 \%)$, which face major land transformation. AU and BU were mostly found along the main road of the island. It spreads as far north as the middle of the Thalang district, as far south as the bottom of the island along with the south-eastern part of the Mueang Phuket district, and as far west as into the Kathu district. AM was observed on the western coast of the island and FM was sparsely marked. A majority of the WM pattern was devoted to the conversion of water bodies (Fig. 3).

\subsection{Impacts of LULC and Change Patterns on LST}

The coefficients of daytime and nighttime LST and their corresponding $p$-values from the GLS model in linear regression analysis for each LST pixel (with a sample size of 690 observations) were shown on the thematic maps in Fig. 4. An increasing or decreasing trend of LST over 15 years from a particular pixel (location) for four different overpassed times was illustrated in Figs. 4(a)-4(d), respectively. Statistical evidence presented by the $p$-value were depicted in Figs. 4(e)-4(h). The daytime LST, in particular at 10:00 [Figs. 4(a) and 4(e)], increases significantly on the east side of the island, especially in the lowland area. The nighttime LST rises significantly almost everywhere. This suggests that the dynamic of daytime LST trends was affected by the different patterns of LULCC, but not for nighttime, where the long-term trend of LST increases with statistical significance over most of the study area. In the case of cooling temperature, most of those pixels were not statistically significant. A declining temperature was only observed at the miscellaneous lands in the midwestern part of the Thalang district [pointed out inside the circle in Figs. 4(b) and 4(f)].

The results from the GLS model showed the evidence of increasing or decreasing trend of LST outcome variable. It allowed us to preliminarily explore its relations to spatial distribution when visualized on maps. Differently, the GEE model was applied to investigate the correlation between LULCC patterns and LST trends. Results from the GEE models with "exchangeable" working correlation structure, as illustrated in Fig. 5, show the effects of LULCC patterns on LST trends with their 95\% CIs. Overall, the daytime LST increased significantly with the change patterns [Fig. 5(a)], whereas the nighttime LST was raised considerably regardless of the change 


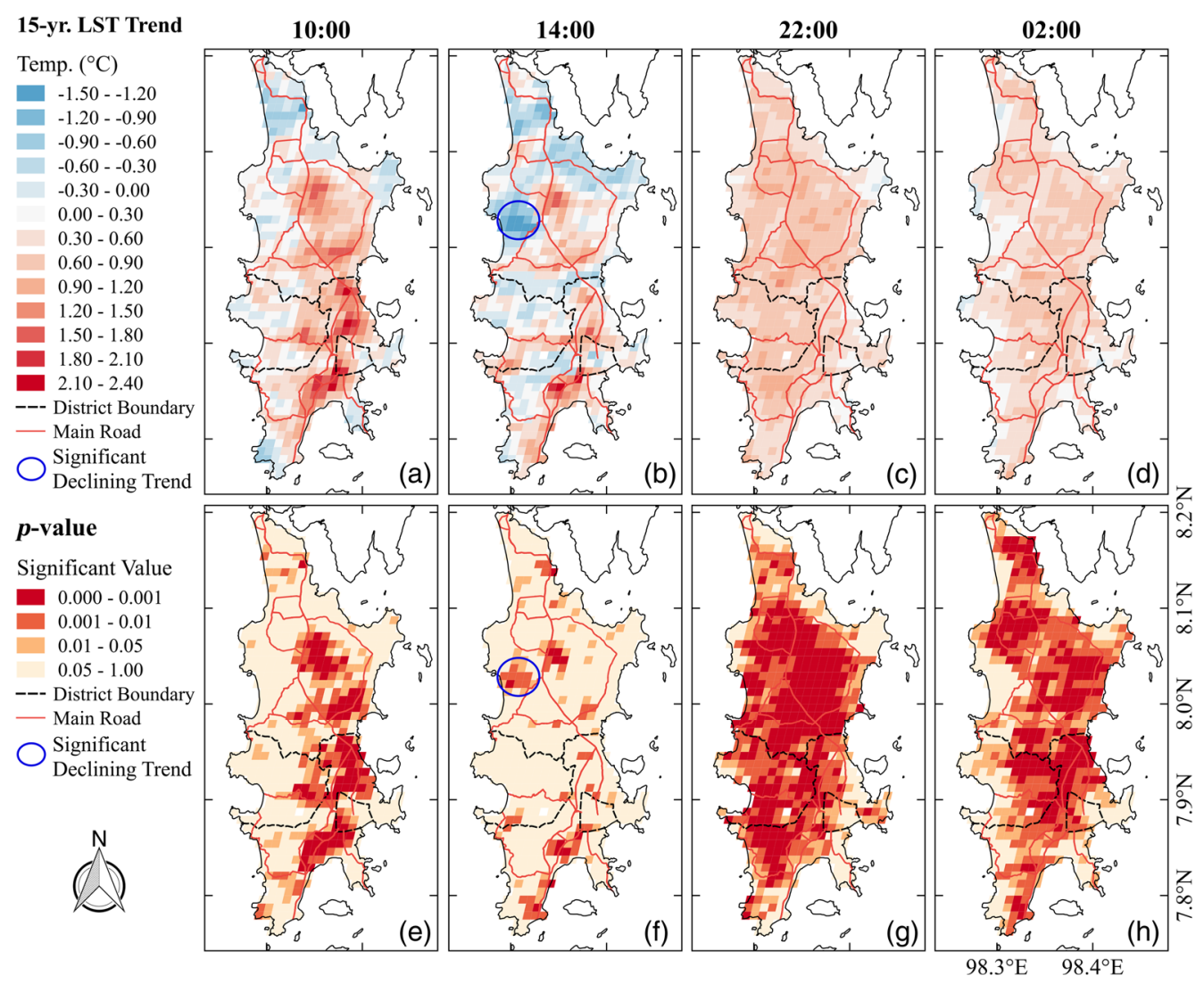

Fig. 4 (a)-(d) Spatial distribution of 15-year surface temperature trends and (e)-(h) maps of $p$-value distribution of surface temperature trends for four overpass-time MODIS LST datasets.

patterns [Fig. 5(b)]. During the nighttime, an increase in LST was strong in both areas where the conversion between land use types, as well as where the increase of area proportion within the same land use type. This shows that the nighttime LST was not influenced by LULCC patterns, suggesting that other factors would have been the causes of its warming dynamics. Note that MODIS LST data only from 611 pixels were used in this analysis since one pixel located over Bang Wad Dam, the biggest reservoir on the island, was not available. The overall trends of daytime LST over the study area increased by $0.4^{\circ} \mathrm{C}$ and $0.14^{\circ} \mathrm{C}$ per 15 years for $10: 00$ and 14:00, respectively. The nighttime LST trends, which were generally warmer than the daytime, increased by $0.62^{\circ} \mathrm{C}$ and $0.50^{\circ} \mathrm{C}$ per 15 years for $22: 00$ and $02: 00$, respectively. At the $95 \% \mathrm{CI}$, 15 -year LST trend over the study area varies between $-0.07^{\circ} \mathrm{C}$ and $1.00^{\circ} \mathrm{C}$ for $10: 00,-0.15^{\circ} \mathrm{C}$ and $0.50^{\circ} \mathrm{C}$ for $14: 00,0.42^{\circ} \mathrm{C}$ and $0.76^{\circ} \mathrm{C}$ for $22: 00$, and $0.38^{\circ} \mathrm{C}$ and $0.62^{\circ} \mathrm{C}$ for $02: 00$. The effects of change patterns in terms of LULC type conversion over time and spatial heterogeneity (coverage proportions) within the specific location were clearly exposed during the 10.00 am observations. Therefore, the following results were based on this overpass time.

For each of the unchanged types over time (AA, FF, and UU), the spatial homogeneity patterns (HoU-A, HoU-F, and HoU-U) experienced a higher rate of rising LST than the heterogeneity patterns (HeU-A, HeU-F, and HeU-U). However, there was no evidence of statistically significant differences as the CIs of the estimated effects were still overlapped. A bigger sample will probably shrink the range of uncertainty associated with the estimates. When comparing the different types, the UU pattern had a higher temperature compared to the other patterns. The rising temperature was ranked in decreasing order for $\mathrm{UU}, \mathrm{BB}, \mathrm{FF}, \mathrm{AA}$, and WW patterns, respectively.

For each of the changed types over the study period (AM, AU, BU, FM, and WM), both the conversions to urban from agriculture land (AU) and bare land (BU) had a higher rate of increasing LST than the transformations to mixed land uses from agriculture land (AM), forest (FM), and water body (WM). There was no significant difference in rising LST among the AM, FM, 

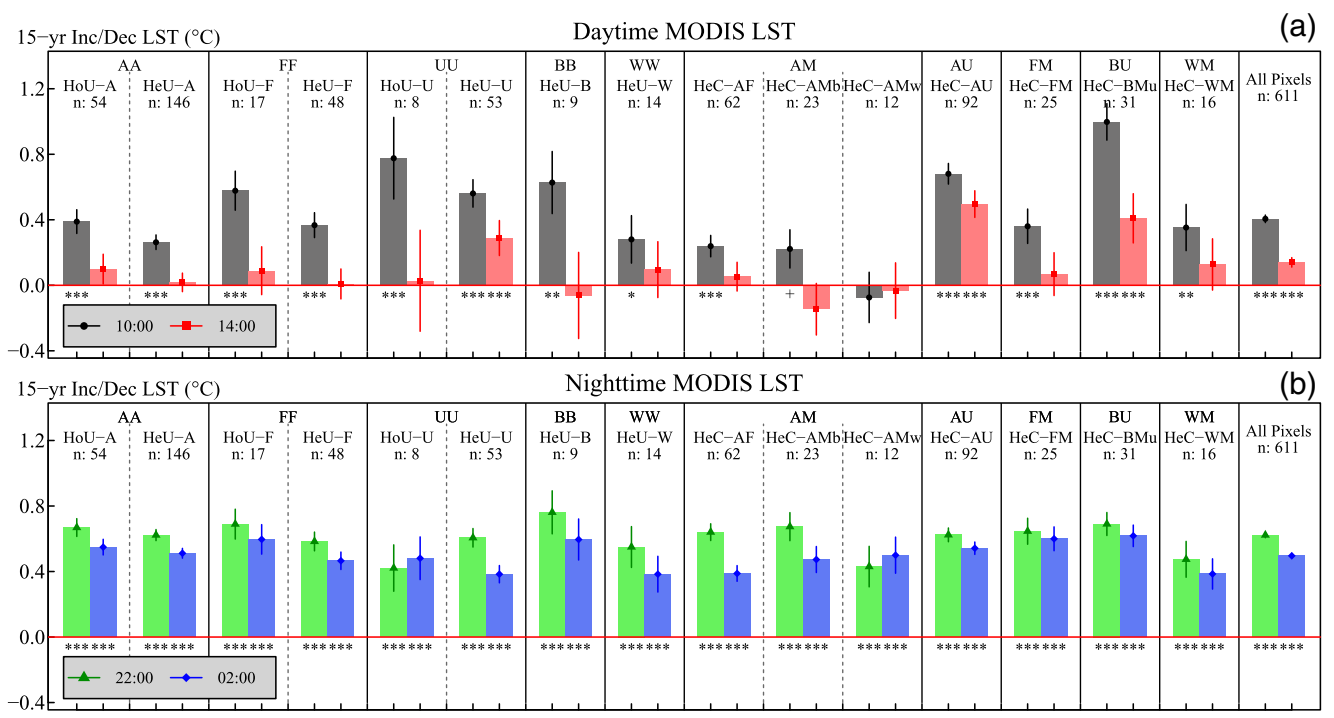

Significant Codes: $0^{\text {**** }} 0.001^{\prime * * \prime} 0.01^{\prime * 1} 0.05^{\prime}++^{\prime} 0.1^{\prime \prime} 1$

Fig. 5 Overall 15-year surface temperature trends in various LULC transformations for the (a) daytime and (b) nighttime MODIS LST datasets. The error bars denote $95 \%$ confidence interval and " $n$ " denotes the number of the LST pixel with a sample size of 690 observations.

and WM patterns, whereas the AU pattern faced a lower rate than the BU pattern with a statistical evidence at the $95 \%$ confidence level.

\subsection{Impacts of Land Cover Heterogeneity on LST}

By using our proposed land cover conversion classification, we can categorize the level of spatial heterogeneity and then quantify its effect on LST trend. The effect of heterogeneity of land conversion in terms of different transition proportions was revealed in Fig. 6. Different LULC types of land cover domination show a different degree of influence on the long-term 10:00 LST trend. A transformation from agriculture to different percentages of dominated urban surface (HeC-AU) resulted in a remarkably rising LST trend. There was strong evidence that an increasing rate of LST over 15 years for such an LULCC pattern with a transition proportion of less than $40 \%$ was significantly lower than that for the pattern with the transition proportions of $40 \%$ to $60 \%, 60 \%$ to $80 \%$, and more than $80 \%$ (CIs being not overlapped). Also, a marginal difference was marked between a transition proportion of $40 \%$ to $60 \%$ and more than $80 \%$. A similar finding was found for the transformation from bare land to mixed land use type with urban being

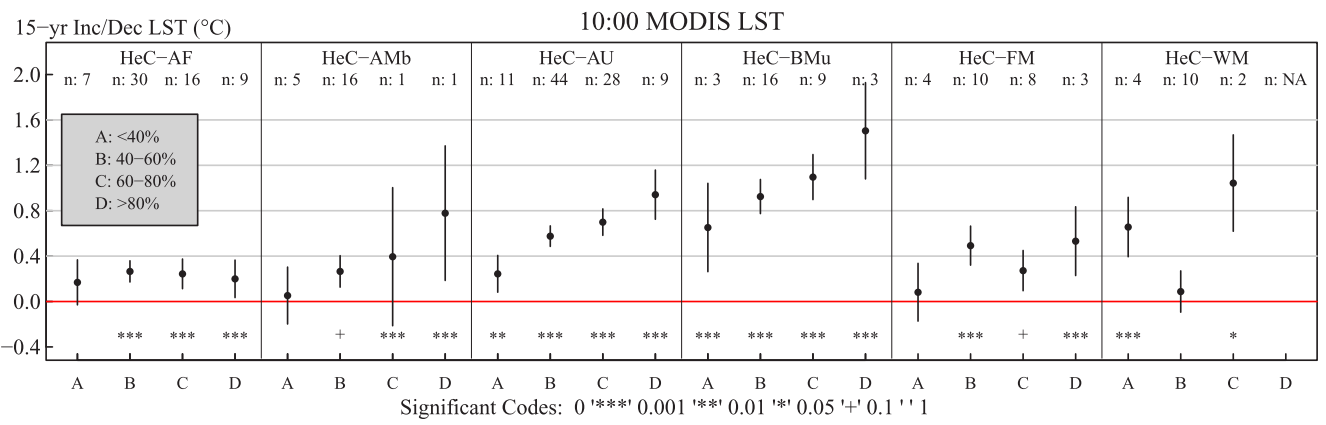

Fig. 6 Overall 15-year surface temperature trends (error bars denote $95 \% \mathrm{Cls}$ ) level of heterogeneity for the 10:00 MODIS LST datasets. "A," "B," "C," and "D" indicate the amount of land cover fragment that the original land cover has been transformed to; "A" is less than $40 \%$ of the total $1 \mathrm{~km} 2$ area, " $\mathrm{B}$ " is $40 \%$ to $60 \%$; " $\mathrm{C}$ " is $60 \%$ to $80 \%$, and " $\mathrm{D}$ " is more than $80 \%$. And " $n$ " denotes the number of the LST pixel with a sample size of 690 observations. 
dominated (HeC-BMu) only for a transition proportion of less than $40 \%$ and more than $80 \%$, and that of $40 \%$ to $60 \%$ and more than $80 \%$ having significant statistical evidence. An increase of sample size (a number of pixels) will aid this circumstance. For HeC-AF pattern, an increasing proportion of forest in the original agriculture lands has no effect on the LST trend. This may be explained by the existing agroforest that combines forest and monoculture rubber plantation in the study area. Other heterogeneous LULCC patterns (HeC-FM and HeC-WM) have no significant trend over the study period.

\section{Discussion}

Diverse patterns and their corresponding spatial heterogeneity of LULC have a significant influence in the study of the long-term variation in LST. Our study pointed out that lands having unchanged LULC types over time (AA, FF, and UU) have less LST variability than those with LULC change patterns from one type to another, particularly the transformations from agriculture land and bare land to urban area (AU and BU). These confirm the conclusions in this study and many previous UHI studies ${ }^{7,25,29,55}$ that LST change is sensitive and strongly relate to the evolution of land cover and is often associated with urbanization. Moreover, our finding was similar to the results from Fall et al. ${ }^{56}$ reporting that converted land types of agriculture, urbanization, and barren solids constituted strong drivers of surface temperature change.

The new urban areas surrounding the Phuket City area and along the main road of $57 \mathrm{~km}$ distance from the north to the south of the island developed significant increasing trends of LST. It is not only the artificial materials in the urban area that have higher heat capacities and conductivities occupying most of the urban surface, but the anthropogenic heat discharge such as energy consumption also contributes to the increase in surface and atmospheric temperatures. ${ }^{25}$ This figure was more evident during the daytime than in the nighttime. LST in response to LULC change patterns depends on the time of the day. Variations in LST due to LULC change patterns were observed clearly during the daytime but not at night. Land surface in the morning time (10:00) has a statistically substantial increasing temperature within all land cover change patterns. On another hand, LST on the land transformation of AU and BU patterns gains temperature significantly in the afternoon (14:00). A similar result was found for the effect of LULCC on the daytime LST. Franco et al. ${ }^{6}$ described that the daytime temperature profiles established a great rising of heat in the conversion to a metropolitan area and a drop of temperature while encountering water bodies and nearby regions. ${ }^{57,58}$ The reduction in vegetal cover and emerging of new urban areas contributes greatly to strengthen the intensity of LST during the daytime. ${ }^{59}$ The finding was also emphasized by magnitudes of nighttime LST that more than $50 \%$ of all pixels (390 and 363 pixels for 22:00 and 02:00 datasets) over the entire study area have a sizeable increasing temperature with great statistical evidence (temperature increases $>0.3^{\circ} \mathrm{C}$ in 15 years and has $p$-value $<0.05)$. Moreover, the graph of comparison CIs of changing daytime surface temperatures (combined 10:00 and 14:00 datasets), as shown in Fig. 7, indicates that the changing temperatures from three groups of urbanized LULCC patterns are above the average statistically significant increasing temperature during 15 years. The highly significant $p$-value $(<0.001)$ resulting from the analysis of variance (ANOVA) test signifies that there are substantial differences in the mean of increasing temperature among the groups of LULCC pattern. In contrast, the comparative confidence interval of the changing temperatures in the nighttime (combined 22:00 and 02:00 datasets) are around the average increasing temperature $\left(0.65^{\circ} \mathrm{C} / 15\right.$ years). The insignificant $p$-value (0.5099) from the ANOVA test implies that there is weak evidence that the changing temperatures among the group of LULCC patterns are different. In other words, nighttime LST increased almost everywhere regardless of diverse patterns of LULCC. To our best knowledge, our study was the first report that pointed out no significant relationship between the nighttime LST long-term trend and LULC conversion. We would recommend that climatic researchers investigate the nighttime LST as one of the Earth's surface biophysical indicators in the process of demonstrating global climate change and global warming.

As mentioned in Sec. 3.2, the LULCC of Phuket Island was caused by rapid economic growth and the population pressure. The study area has experienced enormous changes in LULC. As the result, from transition analysis (Table 4), there is urban expanding continuously 

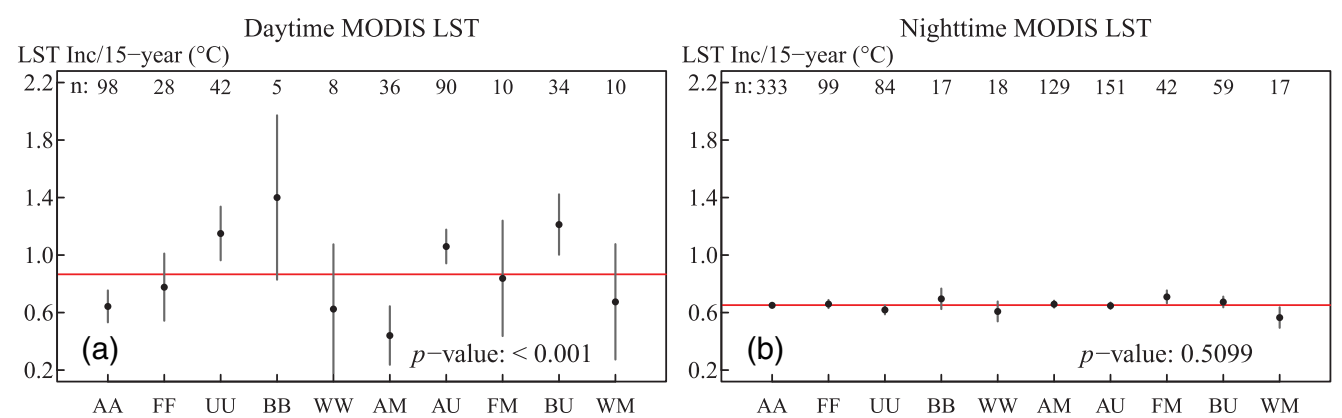

Fig. 7 Comparison of Cls of 15-year changing surface temperature during the study period of 10 LULC change patterns for combined (a) daytime and (b) nighttime LST data. The label " $n$ " indicates the number of LST time series that have a statistically significant surface temperature trend $(p<0.05)$ in each group of land cover change pattern.

from the Phuket City to Kathu and Thalang districts and also along the eastern shoreline of Mueang Phuket district since 2000. According to the studies ${ }^{54,60}$ in the study area, only during the short period, from 2005 to 2009, were the forest conservation and rural/agricultural areas transformed into residential areas by $3.19 \%$ and $10.95 \%$, respectively. The study of LULCC in Phuket for over 23 years (1989-2011) disclosed that built-up areas had replaced all types of land use. Those lands mostly were the agricultural regions, such as coconut orchards $(27.35 \%)$, paddy fields $(24.51 \%)$, and para-rubber plantations $(15.5 \%) .{ }^{30}$ Similar to the result, Thinnukool et al. ${ }^{61}$ discovered that the agricultural area had changed to urban area by $19 \%$ only in a decade (2000 to 2009). These previous reports were in agreement with our findings of LULC transitions during the 15-year study period. However, the replacing of humanmade built-up surface on vegetation cover within each LST grid size in the study area was assumed to be gradually changed. An infrequent occasion of $1 \mathrm{~km}^{2}$ land cover has been entirely transformed in the short period, except for natural disasters that could affect the broad area coverage. Thus, the gradual conversion of LULC was assumed to slowly modify the surface temperature and its long-term trend, resulting in variation in the temperature trend within the group of land conversion patterns. This assumption also applies a nonchanging urban surface, where some unchanged urban areas in the study area could raise its surface temperature trend due to the variation of its surface density. There is a possibility that the urban area classified in 2000 was a low density of buildings and then turned to a high-density surface in 2016, which could cause an increasing temperature trend.

There was also the area that shows a declining trend of surface temperature with a highly statistical significance, as pointed out inside the circle in Figs. 4(b) and 4(f). It is located in the midwestern part of Thalang district. This cooling trend occurring in the 14:00 LST dataset was due to many water bodies that have been introduced into the area. Before 2000, this area was abandoned open ground tin mines and neglected paddy fields. Since 2000, many waterfront resorts and hotels, including lake and lagoon-style housing estates, golf courts, and green spaces, have been developed. ${ }^{62}$ The water body has a low surface temperature during the daytime because it absorbs more radiant energy from solar radiation to escalate its heat capacity ${ }^{63}$ and the green spaces may cause the cooling trend. Moreover, water consumption such as water spraying in the parks and the golf court during the day may be other factors of decreasing temperature trend in this area.

Spatial heterogeneity has evidently impacted the variability in LST in this study. The spatial heterogeneity patterns diminish the growth rate of LST. Land surfaces with heterogeneous land cover have a lower magnitude of rise in their temperature than those with homogenous land cover. This urges researchers who have studied in a field of the LULCC effects on LST trends to pay more attention to the proportions of area coverage within a pixel of different LULC types. Previous studies had been assuming spatial homogeneity for simplicity. Our approach in spatial heterogeneity identification was complex but affordable and thus improved our insight understanding about a relatively strong effect of a combination of LULC types in a given area on LST. In practice, when it comes to set up a plan for land management, such as a proportion of green belt in a particular building region for environmental sustainability, spatial heterogeneity will give more precise vision and accuracy sense. 
In traditional statistical analysis, an exploratory analysis is the first step to exploring a sample known as "let data tell its story," and then an appropriate statistical method was applied for a testing hypothesis to conclude the population. Previous studies often carried out an exploratory study rather than go further for confirmation with a statistical model. One of the reasons may be the use of an anomaly measure that reduces the number of original data, resulting in not enough sample size for further analysis. Our approach of seasonally adjusted LST using a cubic spline method resolves this problem and is recommended to apply on a broader area. A conclusion with a statistical validation will provide better evidence for the decision-making process. As in this present study, we confirmed our descriptive explanation from the visualization maps with the 95\% confidence that LST increases significantly with AU and BU using the regression analysis with the GEE model.

\section{Conclusions}

In this study, we investigated the impacts of different transformed LULC characteristics (i.e., types and spatial heterogeneity) on the long-term dynamic and trend of MODIS LST time series of Phuket Island from 2003 to 2017. The 15-year LST time series were seasonally adjusted using a cubic spline function to eliminate seasonal effect and were subsequently estimated as a 15-year linear trend in a series-by-series procedure (pixel-by-pixel) using the GLS model in regression analysis. Finally, the effects of LULCC patterns were investigated using the GEE model.

The long-term trends of seasonally adjusted LST vary with the time of the day and in the different areas of LULC conversion depending on types and heterogeneity patterns. This LULCC factor remarkably contributed to the increasing trend and variation of LST only in the daytime. It did not affect the nighttime LST dynamics. It suggests that the nighttime temporal MODIS LST data would be applicable for a short- or long-term surface temperature trend and climate change studies in any study area. Since the evolution of LULCC types and spatial heterogeneity between two periods were the strong factors affecting a change in LST trend, the morning MODIS LST data is, on the other hand, suitable for a study of LULCC impact of LST trend, particularly for urbanization and UHI effect. The spatial heterogeneity patterns exhibited a lower rate of rising surface temperature than the spatial homogeneity patterns. In addition, the greater the proportion of land cover transition, the higher the rate of increasing temperature, especially for conversions from cultivated agriculture land to built-up land. These suggested the importance of spatial heterogeneity effects in the study of LST dynamics and long-term trends.

Even though our study area is relatively small and has high surface heterogeneity, which presents a small number of sample sizes for individual conversion patterns, the result for this study is still providing high certainly in evidence. Performing this similar analysis that concerns preserving the number of original data in the larger study area could increase the number of sample size and therefore could confirm the impacts of the spatial heterogeneity on LST changes and also prove the variability and validity of the nighttime LST trend. The comprehensive knowledge of the underlying mechanisms of Earth's surface temperature, land conversion patterns, and their relationships is vital to decision-making processes in responses to climate change that will improve the scientific basis of future planning and regulations. This study also provides a methodological guideline for trend analysis of satellite-based climate time series data in climate science studies in which regional or global coverages are desired.

\section{Acknowledgments}

This research had been supported by Scholarship Awards for Thai $\mathrm{PhD}$ students under Thailand's Education Hub for Southern Region of ASEAN Countries and Overseas Thesis Research Scholarship from Graduate School, Prince of Songkla University, attributed to Noppachai Wongsai. This study was partially funded by the Centre of Excellence in Mathematics, the Commission on Higher Education, Thailand. The constructive comments and suggestions from the anonymous reviewers are very gratefully acknowledged. 


\section{References}

1. R. M. Ramachandran et al., "Long-term land use and land cover changes (1920-2015) in Eastern Ghats, India: pattern of dynamics and challenges in plant species conservation," Ecol. Indic. 85, 21-36 (2018).

2. B. McGill, "Biodiversity: land use matters," Nature 520, 38-39 (2015).

3. T. Newbold et al., "Global effects of land use on local terrestrial biodiversity," Nature 520, 45-50 (2015).

4. Z. Sun et al., "Long-term effects of land use/land cover change on surface runoff in urban areas of Beijing, China," J. Appl. Remote Sens. 8(1), 084596 (2013).

5. X.-L. Chen et al., "Remote sensing image-based analysis of the relationship between urban heat island and land use/cover changes," Remote Sens. Environ. 104, 133-146 (2006).

6. S. Franco et al., "Study of temperature profile on various land use and land cover for emerging heat island," J. Urban Environ. Eng. 9(1), 32-37 (2015).

7. G. R. F. Ibrahim, "Urban land use land cover changes and their effect on land surface temperature: case study using Dohuk City in the Kurdistan region of Iraq," Climate 5, 13 (2017).

8. A. Rasul, H. Balzter, and C. Smith, "Applying a normalized ratio scale technique to assess influences of urban expansion on land surface temperature of the semi-arid city of Erbil," Int. J. Remote Sens. 38(13), 3960-3980 (2017).

9. R. Amiri et al., "Spatial-temporal dynamics of land surface temperature in relation to fractional vegetation cover and land use/cover in the Tabriz urban area, Iran," Remote Sens. Environ. 113, 2606-2617 (2009).

10. S. N. A. Buyadi, W. M. N. W. Mohd, and A. Misni, "Impact of land use changes on the surface temperature distribution of area surrounding the National Botanic Garden," Proc. Soc. Behav. Sci. 101, 516-525 (2013).

11. N. M. Haddad et al., "Habitat fragmentation and its lasting impact on Earth's ecosystems," Sci. Adv. 1(2), e1500052 (2015).

12. O. Singh, N. Kikon, and P. Verma, "Impact of land use change and urbanization on urban heat island in Lucknow city, Central India. A remote sensing based estimate," Sustain. Cities Soc. 32, 100-114 (2017).

13. S. Pal and S. Ziaul, "Detection of land use and land cover change and land surface temperature in English Bazar urban centre," Egypt. J. Remote Sens. Space Sci. 20, 125-145 (2017).

14. B. B. Lin et al., "Local- and landscape-scale land cover affects microclimate and water use in urban gardens," Sci. Total Environ. 610-611, 570-575 (2018).

15. Z. Li et al., "Land use/cover change and regional climate change in an arid grassland ecosystem of Inner Mongolia, China," Ecol. Modell. 353, 86-94 (2017).

16. S. López, C. Wright, and P. Costanza, "Environmental change in the equatorial Andes: linking climate, land use, and land cover transformations," Remote Sens. Appl. Soc. Environ. 8, 291-303 (2017).

17. L. M. Kueppers et al., "Seasonal temperature responses to land-use change in the western United States," Global Planet. Change 60, 250-264 (2008).

18. H. Zhang et al., "Analysis of land use/land cover change, population shift, and their effects on spatiotemporal patterns of urban heat islands in metropolitan Shanghai, China," Appl. Geogr. 44, 121-133 (2013).

19. Q. Weng, "Fractal analysis of satellite-detected urban heat island effect," Photogramm. Eng. Remote Sens. 69, 555-566 (2003).

20. R. C. Hale, K. P. Gallo, and T. R. Loveland, "Influences of specific land use/land cover conversions on climatological normals of near-surface temperature," J. Geophys. Res. 113 , D14113 (2008).

21. D. X. Tran et al., "Characterizing the relationship between land use land cover change and land surface temperature," ISPRS J. Photogramm. Remote Sens. 124, 119-132 (2017).

22. H. Ding and W. Shi, "Land-use/land-cover change and its influence on surface temperature: a case study in Beijing City," Int. J. Remote Sens. 34(15), 5503-5517 (2013). 
23. M. Sahana, R. Ahmed, and H. Sajjad, "Analyzing land surface temperature distribution in response to land use/land cover change using split window algorithm and spectral radiance model in Sundarban Biosphere Reserve, India," Model. Earth Syst. Environ. 2, 81 (2016).

24. N. Kayet et al., "Spatial impact of land use/land cover change on surface temperature distribution in Saranda Forest, Jharkhand," Model. Earth Syst. Environ. 2, 127 (2016).

25. J.-J. Li et al., "Remote sensing evaluation of urban heat island and its spatial pattern of the Shanghai metropolitan area, China," Ecol. Complex. 6, 413-420 (2009).

26. Y. Xiong et al., "The impacts of rapid urbanization on the thermal environment: a remote sensing study of Guangzhou, South China," Remote Sens. 4, 2033-2056 (2012).

27. M. E. Hereher, "Effects of land use/cover change on regional land surface temperatures: severe warming from drying Toshka lakes, the Western Desert of Egypt," Nat. Hazards 88, 1789-1803 (2017).

28. P. Fu and Q. Weng, "A time series analysis of urbanization induced land use and land cover change and its impact on land surface temperature with Landsat imagery," Remote Sens. Environ. 175, 205-214 (2016).

29. Y. Zhang and S. Liang, "Impacts of land cover transitions on surface temperature in China based on satellite observations," Environ. Res. Lett. 13, 024010 (2018).

30. N. Payakka and S. Wongsai, "Historical land use and land cover changes, 1989-2011, in Phuket, Thailand," in 1st Annu. PSU Phuket Int. Conf. 2012, Phuket, Thailand (2013).

31. ORNL DAAC Team, "Global subsets tool: MODIS/VIIRS land products," https://modis .ornl.gov/cgi-bin/MODIS/global/subset.pl (accessed 15 July 2017).

32. N. Wongsai, S. Wongsai, and A. R. Huete, "Annual seasonality extraction using the cubic spline function and decadal trend in temporal daytime MODIS LST data," Remote Sens. 9(12), 1254 (2017).

33. Z. Wan, "Collection-6 MODIS land surface temperature products users' guide," 2013, https://lpdaac.usgs.gov/documents/118/MOD11_User_Guide_V6.pdf (accessed 12 October 2018).

34. Z. Wan and Z.-L. Li, "Radiance-based validation of the V5 MODIS land-surface temperature product," Int. J. Remote Sens. 29(7), 5373-5395 (2008).

35. C. Coll, Z. Wan, and J. M. Galve, "Temperature-based and radiance-based validations of the V5 MODIS land surface temperature product," J. Geophys. Res-Atmos. 114, D20102 (2009).

36. Z. Wan, "New refinements and validation of the collection-6 MODIS land-surface temperature/emissivity product," Remote Sens. Environ. 140, 36-45 (2014).

37. A. Reinart and M. Reinhold, "Mapping surface temperature in large lakes with MODIS data," Remote Sens. Environ. 112(2), 603-611 (2008).

38. G. C. Hulley, S. J. Hook, and P. Schneider, "Optimized split-window coefficients for deriving surface temperatures from inland water bodies," Remote Sens. Environ. 115(12), 3758-3769 (2011).

39. E. T. Crosman and J. D. Horel, "MODIS-derived surface temperature of the Great Salt Lake," Remote Sens. Environ. 113(1), 73-81 (2009).

40. C. Coll et al., "Ground measurements for the validation of land surface temperatures derived from AATSR and MODIS data," Remote Sens. Environ. 97(3), 288-300 (2005).

41. K. Wang and S. Liang, "Evaluation of ASTER and MODIS land surface temperature and emissivity products using long-term surface longwave radiation observations at SURFRAD sites," Remote Sens. Environ. 113, 1556-1565 (2009).

42. J. Zhou et al., "The GLASS land surface temperature product," IEEE J-STARS 12, 493-507 (2019).

43. L. Lu et al., "Evaluation of collection-6 MODIS land surface temperature product using multi-year ground measurements in an arid area of Northwest China," Remote Sens. 10(11), 1852 (2018).

44. QGIS Development Team, "QGIS geographic information system," Open Source Geospatial Foundation Project, 2018, http://qgis.osgeo.org (accessed 5 January 2018).

45. L. Giglio et al., "Collection 6 MODIS burned area product user's guide," Version 1.2, http://modis-fire.umd.edu/files/MODIS_C6_BA_User_Guide_1.2.pdf (accessed 20 October 2018). 
46. R Core Team, $R$ : A Language and Environment for Statistical Computing, R Foundation for Statistical Computing, Vienna, Austria (2018).

47. J. C. Pinheiro et al., "NLME: linear and nonlinear mixed effects models," $R$ Package Version 3.1-137, 2018, https://CRAN.R-project.org/package=nlme (accessed 28 November 2018).

48. G. E. P. Box, G. M. Jenkins, and G. C. Reinsel, Time Series Analysis: Forecasting and Control, 3rd ed., Holden-Day, California (1994).

49. J. C. Pinheiro and D. M. Bates, Mixed-Effects Models in S and S-PLUS, pp. 235, 397, Springer, New York (2000).

50. S. Højsgaard, U. Halekoh, and J. Yan, "The R package geepack for generalized estimating equations," J. Stat. Software 15(2), 1-11 (2006).

51. M. Wang, "Generalized estimating equations in longitudinal data analysis: a review and recent developments," Adv. Stat. 2014, 303728 (2014).

52. K. Liang and S. L. Zeger, "Longitudinal data analysis using generalized linear models," Biometrika 73, 13-22 (1986).

53. S. L. Zeger, K. Y. Liang, and P. S. Albert, "Models for longitudinal data: a generalized estimating equation approach," Biometrics 44, 1049-1060 (1988).

54. P. Buaphun and S. Wongsai, "Land use change and the Town Planning Policy of Phuket," in 33rd Asian Conf. Remote Sens. (ACRS), Pattaya, Thailand (2012).

55. J. Li et al., "Impacts of landscape structure on surface urban heat islands: a case study of Shanghai, China," Remote Sens. Environ. 115, 3249-3263 (2011).

56. S. Fall et al., "Impacts of land use land cover on temperature trends over the continental United States: assessment using the North American Regional Reanalysis," Int. J. Climatol. 30(13), 1980-1993 (2010).

57. D. Mutiibwa, A. Kilic, and S. Irmak, "The effect of land cover/land use changes on the regional climate of the USA high plains," Climate 2, 153-167 (2014).

58. N. Gupta, A. Mathew, and S. Khandelwal, "Analysis of cooling effect of water bodies on land surface temperature in nearby region: a case study of Ahmedabad and Chandigarh cities in India," Egypt. J. Remote Sens. Space Sci. 22(1), 81-93 (2019).

59. A. Ayanlade, "Seasonality in the daytime and night-time intensity of land surface temperature in a tropical city area," Sci. Total Environ. 558(4), 415-424 (2016).

60. P. Chuangchang, T. Sangkhaduang, and P. Tongkumchum, "Modelling developed land in Phuket Province of Thailand: 2000-2009," Pertanika J. Soc. Sci. Hum. 24(2), 795-809 (2016).

61. O. Thinnukool, N. Kongchouy, and C. B. Appianing, "Management of LUCC and land-use transition in Phuket Island, Thailand," Int. J. Comp. Electr. Eng. 6(2), 176-180 (2014).

62. O. Thinnukool, N. Kongchouy, and C. Choonpradub, "Detection of land use change using the R program (A case study of Phuket Island, Thailand)," Res. J. Appl. Sci. 9(5), 228-237 (2014).

63. E. H. Alcântara et al., "Remote sensing of water surface temperature and heat flux over a tropical hydroelectric reservoir," Remote Sens. Environ. 114(11), 2651-2665 (2010).

Noppachai Wongsai was a senior lecturer at Prince of Songkla University (PSU), Phuket campus. He is now a $\mathrm{PhD}$ candidate in research methodology. Since his backgrounds are computer engineering (BE) and IT (MSc), his main research interests include data sciences in geoinformatics for environment and climate.

Sangdao Wongsai is an assistant professor and a lecturer at Thammasat University. She received her $\mathrm{PhD}$ in applied statistics from Macquarie University in Sydney, Australia. She teaches spatial statistics, geoinformatics research methodology, and GIS applications for graduate and undergraduate courses. Her main research interests include data sciences in the environment, ecology, renewable energy, land and water, and tourism management. She is a member of the International Statistic Institute (ISI).

Apiradee Lim is an associate professor and a lecturer at the Faculty of Science and Technology, Prince of Songkla University, Pattani campus. After she finished her PhD in research methodology in 2009, she continues to apply statistics in epidemiology and many research fields. Her current research interests include developing appropriate statistical methodologies in 
epidemiology, healthcare, and fresh and brackish water ecosystem. She is a member of the International Statistic Institute (ISI).

Don McNeil is a visiting professor at Prince of Songkla University (PSU), Pattani campus. After his $\mathrm{PhD}$, he spent 8 years in the US, gaining tenure at Princeton University before returning to Australia as foundation professor of statistics at Macquarie University. He set up a high-quality $\mathrm{PhD}$ program in epidemiology and research methodology at PSU Pattani campus, where he now spends a lot of his "retirement" time advising many Thai and international students in the program.

Alfredo R. Huete is a distinguished professor, who leads the Ecosystem Dynamics Health and Resilience research program within the School of Life Sciences, University of Technology Sydney. He is lead developer of the enhanced vegetation index (EVI), which has been implemented in MODIS vegetation indices products. His current research interests include land-ocean interactions and feedback, functional phenology measures, and climate-induced biome shifts in seasonality. He is a member of ISPRS, AGU, SSSI, IEEE, and ATBC. 